\title{
MONOMERIC TETRAHYDROFURAN-STABILIZED MOLYBDENUM(III) HALIDES
}

\author{
Submitted by RINALDO POLI, ${ }^{* \dagger}$ STEVEN T. KRUEGER, ${ }^{*}$ and SUNDEEP P. \\ MATTAMANA* \\ Checked by KIM R. DUNBAR ${ }^{\star}$ and ZHAO HANHUA* \\ * Department of Chemistry and Biochemistry, University of Maryland, College Park, MD 20742. \\ ${ }^{\dagger}$ Current address: Laboratoire de Synthèse et d'Electrosynthèse Organométalliques, Faculté de \\ Sciences "Gabriel,” 6 Boulevard Gabriel, 21100 Dijon, France. \\ \$ Department of Chemistry, Michigan State University, East Lansing, MI 48824.
}


Monomeric, soluble Mo(III) precursors are extremely useful chemical intermediates, their uses ranging from transformation to other $\mathrm{Mo}(\mathrm{III})$ coordination compounds, ${ }^{1}$ reduction to dinitrogen complexes, ${ }^{2}$ conversion to metal-metal bonded compounds ${ }^{3}$ and formation of new materials. ${ }^{4}$

There have been several reports of the preparation of $\mathrm{MoCl}_{3}(\mathrm{THF})_{3}$, all based on reductive procedures starting from $\mathrm{MoCl}_{5}{ }^{1,2,5-7}$ These procedures cannot be extended to the corresponding bromide $^{8}$ and iodide ${ }^{9}$ compounds for lack of suitable higher-valent precursors, The alternative approach developed for these two compounds ${ }^{9,10}$ and reported here is based on the oxidative decarbonylation of lower-valent carbonyl precursors. For the preparation of the bromide compound, the commercially available $\mathrm{Mo}(\mathrm{CO})_{6}$ is a suitable starting compound. For the preparation of the iodide compound, on the other hand, $\mathrm{Mo}(\mathrm{CO})_{6}$ is not sufficiently reactive to be oxidized by $\mathrm{I}_{2}$ and the more reactive $\left(\eta^{6}-\mathrm{C}_{6} \mathrm{H}_{5} \mathrm{CH}_{3}\right) \mathrm{Mo}(\mathrm{CO})_{3}$ is used instead. Because the latter compound is not commercially available and its preparation ${ }^{11}$ has not been previously described in Inorganic Synthesis, we also report here a detailed description of its synthesis.

\section{A. TRIBROMOTRIS(TETRAHYDROFURAN)MOLYBDENUM(III), $\left[\mathrm{MoBr}_{3}(\mathrm{THF})_{3}\right]^{10}$}

$$
\begin{gathered}
2 \mathrm{Mo}(\mathrm{CO})_{6}+2 \mathrm{Br}_{2} \longrightarrow\left[\mathrm{Mo}(\mathrm{CO})_{4} \mathrm{Br}_{2}\right]_{2}+4 \mathrm{CO} \\
{\left[\mathrm{Mo}(\mathrm{CO})_{4} \mathrm{Br}_{2}\right]_{2}+4 \mathrm{THF} \longrightarrow 2 \mathrm{MoBr}_{2}(\mathrm{CO}) 3(\mathrm{THF})_{2}+2 \mathrm{CO}} \\
2 \mathrm{MoBr}_{2}(\mathrm{CO})_{3}(\mathrm{THF})_{2}+\mathrm{Br}_{2}+2 \mathrm{THF} \longrightarrow 2 \mathrm{MoBr}_{3}(\mathrm{THF})_{3}+6 \mathrm{CO}
\end{gathered}
$$

- Caution. Br2 is a corrosive liquid with toxic vapors; it should he handled under a fame hood by wearing protective gloves.

- Caution. CO is a toxic gas and all operations should be carried out in a well-ventilated fume hood. 
Hexacarbonylmolybdenum(0) (2.22 g, $8.42 \mathrm{mmol})$ is placed in a 250-mL, round-bottomed flask fitted with a ground glass neck, a side arm with ground-glass stopcock, and a magnetic stir bar. The flask is connected through the side arm to a gas inlet tube of a Schlenk line. The flask is evacuated and the atmosphere is replaced with purified nitrogen. Freshly distilled (under dinitrogen over $\mathrm{P}_{4} \mathrm{O}_{10}$ ) dichloromethane $(25 \mathrm{~mL})$ is introduced into the flask and the apparatus is then cooled to $-78^{\circ} \mathrm{C}$ with a dry ice-acetone bath. Then $\mathrm{Br}_{2}(0.40 \mathrm{~mL}, 7.8 \mathrm{mmol})$ is added to the mixture, which is stirred at $-80^{\circ} \mathrm{C}$ for $1 \mathrm{~h}$ and then allowed to warm to room temperature. The flask stopcock is left open to allow $\mathrm{CO}$ to escape through the Schlenk line during this procedure. Once the solution has reached room temperature, the solvent is completely removed by evaporation under reduced pressure. The solid residue of $\left[\mathrm{Mo}(\mathrm{CO})_{4} \mathrm{Br}_{2}\right]_{2}$ is dissolved into THF $(50 \mathrm{~mL})$ with the evolution of more $\mathrm{CO}$ gas and formation of a red solution. This solution is now cooled to $0^{\circ} \mathrm{C}$ in an ice water bath, followed by the addition of more $\mathrm{Br}_{2}(0.20 \mathrm{~mL}, 3.9 \mathrm{mmol})$. Evolution of gas is once again observed. The mixture is stirred at $0^{\circ} \mathrm{C}$ for $2 \mathrm{~h}$ and then overnight at room temperature. This treatment results in the precipitation of the product as a salmon-pink powder. Stirring should not be continued for a longer period of time, because this causes the product to redissolve in the reaction mixture with formation of unknown, presumably oxygen-containing decomposition materials, derived by oxygen abstraction from THF. A gas-chromatographic analysis of the solution indicates the presence of 1,4dibromobutane. The product is filtered off through a glass frit, thoroughly washed with THF, and dried under vacuum. The yield is $3.72 \mathrm{~g}(80 \%)$.

Anal. Calcd. for $\mathrm{C}_{12} \mathrm{H}_{24} \mathrm{Br}_{3} \mathrm{MoO}_{3}$ : C, 26.11; H, 4.38; Br, 43.43. Found: C, 26.15; H, 4.62; Br, 43.84 .

\section{Properties}

Tribromotris(tetrahydrofuran)molybdenum(III) is a salmon-pink powder. It deteriorates upon exposure to the laboratory atmosphere, but no significant change is observable upon rapid ( $<5 \mathrm{~min})$ handling in air. It is soluble in dichloromethane and chloroform, where it rapidly loses THF to afford 
dinuclear edge-sharing bioctahedral and face-sharing bioctahedral products. ${ }^{12}$ lts molecular stereochemistry is meridional both in solution ${ }^{12}$ and in the solid state. ${ }^{13}$ Its IR spectrum shows a strong vibration for coordinated THF at $840 \mathrm{~cm}^{-1}$. The IR fingerprint region overlaps almost exactly with that of the corresponding $\mathrm{MoCl}_{3}(\mathrm{THF})_{3}$. The compound is only sparingly soluble in $\mathrm{THF}$, and a prolonged standing in a THF solution result in its decomposition as outlined above. This decomposition is accelerated by heating. It can, however, be conveniently used as a starting material in THF in combination with reagents that consume it rapidly at room temperature (e.g., within a few hours). Its reactions with phosphine ligands have been described. ${ }^{10}$

\section{B. TRICARBONYLTOLUENEMOLYBDENUM(0), $\left[\left(\eta^{6}-\mathrm{C}_{6} \mathrm{H}_{5} \mathrm{CH}_{3}\right) \mathrm{Mo}(\mathrm{CO})_{3}\right]^{11}$}

$$
\mathrm{Mo}(\mathrm{CO})_{6}+\mathrm{C}_{6} \mathrm{H}_{5} \mathrm{CH}_{3} \longrightarrow \mathrm{Mo}(\mathrm{CO})_{3}\left(\eta^{6}-\mathrm{C}_{6} \mathrm{H}_{5} \mathrm{CH}_{3}\right)
$$

- Caution. CO is a toxic gas and all operations should be carried out in a well-ventilated fume hood.

Hexacarbonylmolybdenum $(0)(9.00 \mathrm{~g}, 33.1 \mathrm{mmol})$ is placed in a $250-\mathrm{n} 1 \mathrm{~L}$, round-bottomed flask fitted with a ground glass neck, and a side-arm with ground glass stopcock. To the ground glass neck was attached a water-cooled reflux condenser, which was connected at the top with a mineral oil bubbler. The material was suspended in $100 \mathrm{~mL}$ of toluene. The flask was protected from light by wrapping aluminum foil around it and the mixture was brought to a gentle reflux via an oil bath. All the starting compound dissolves before reaching the reflux temperature. Sublimation of small amounts of $\mathrm{Mo}(\mathrm{CO})_{6}$ to the bottom of the condenser is observed at the initial stages of the reaction, but this subsequently disappears as the starting material is converted to the product, while the solution turns canary yellow. Reflux was continued until termination of the CO evolution (48 h), as is evident from the mineral oil bubbler. After cooling to room temperature, the clear yellow solution is reduced 
in volume by evaporation under reduced pressure. The evaporation is stopped when copious amounts of the product start to crystallize from the solution (ca. $10 \mathrm{~mL}$ ). At this point, $50 \mathrm{~mL}$ of $n$-heptane are rapidly added with stirring. More product crystallizes in the form of yellow microcrystals that rapidly settle at the bottom of the flask. The precipitation is further aided by cooling to $-20^{\circ} \mathrm{C}$ overnight. The solid is now recovered by filtration through a coarse glass frit, washed with $n$-heptane $(2 \times 5 \mathrm{~mL})$, and dried under vacuum. The yield is $8.82 \mathrm{~g}(95 \%)$. The material as obtained by this procedure is spectroscopically pure and can be used directly for the preparation of $\mathrm{MoI}_{3}(\mathrm{THF})_{3}$ (see Section C). A common problem of this synthesis is the decomposition of the product to a black insoluble and pyrophoric powder (presumably metallic Mo), which is possibly caused by the use of an impure starting material, to the adventitious introduction of air, to excessive exposure to light, or to a combination of those factors. If a black powder is formed, this can be removed at the end of the reaction by filtration through a glass frit; the subsequent workup is as described above. Such decomposition reduces the yield but does not lead to a less pure product. If larger amounts of $\mathrm{Mo}(\mathrm{CO})_{6}$ are used, the sublimation of larger quantities of $\mathrm{Mo}(\mathrm{CO})_{6}$ to the condenser occurs, which may require interruption of the procedure and manual scraping of the sublimed solid back into the flask with a spatula under a flow of $\mathrm{N}_{2}$. A variety of cosolvents can be used as catalysts for this reaction (e.g., diglyme, $\mathrm{MeCN}$, or 1,4-dioxane). For instance, the use of 1,4-dioxane catalyst (0.5 mL, $5.8 \mathrm{mmol})$ in a synthetic procedure starting from $\mathrm{Mo}(\mathrm{CO})_{6}(4.88 \mathrm{~g}, 18.48 \mathrm{mmol})$ in $50 \mathrm{~mL}$ of toluene has reduced the reflux time to $16 \mathrm{~h}$ and has led to the formation of $4.00 \mathrm{~g}$ of spectroscopically pure product $\left(80 \%\right.$ yield). In our hands, the use of $\mathrm{MeCN}$ leads to impurities of $\mathrm{Mo}(\mathrm{CO})_{3}(\mathrm{MeCN})_{3}$ in the final product.

\section{Properties}

Tricarbonyltoluenemolybdenum( $(0)$ is a yellow crystalline solid, stable in air for brief periods of time as a solid but quite sensitive to air in solution. Prolonged exposure to air leads to the formation of a black insoluble material. The compound is also sensitive to light, especially in solution at high 
temperatures. It is sparingly soluble in saturated hydrocarbons and very soluble in arenes. The compound reacts with donor solvents with exchange of the toluene ligand. For instance, dissolution in $\mathrm{MeCN}$ leads to $\mathrm{Mo}(\mathrm{CO})_{3}(\mathrm{MeCN})_{3}$. Exposure to $\mathrm{CO}$ at 1 atm slowly leads to $\mathrm{Mo}(\mathrm{CO})_{6}$, but this reaction is catalyzed by a number of compounds, including $\mathrm{I}_{2} \cdot{ }^{14}$ The compound shows two strong IR absorptions in the CO stretching region at $1969\left(\mathrm{~A}_{1}\right)$ and $1889(\mathrm{E}) \mathrm{cm}^{-1}$ in toluene solution, or at 1983 and $1911 \mathrm{~cm}^{-1}$ in $n$-heptane solution.

\section{TRIIODOTRIS(TETRAHYDROFURAN)MOLYBDENUM(III), [MoI3(THF)s] ${ }^{9}$}

$$
\begin{gathered}
\mathrm{Mo}(\mathrm{CO})_{3}\left(\eta^{6}-\mathrm{C}_{6} \mathrm{H}_{5} \mathrm{CH}_{3}\right)+3 \mathrm{THF} \longrightarrow \mathrm{Mo}(\mathrm{CO})_{3}(\mathrm{THF})_{3} \\
\mathrm{Mo}(\mathrm{CO})_{3}(\mathrm{THF})_{3} \longrightarrow \mathrm{MoI}_{3}(\mathrm{THF})_{3}+3 \mathrm{CO}
\end{gathered}
$$

- Caution. CO is a toxic gas and all operations should be carried out in a well-ventilated fume hood.

A 250-mL round-bottomed flask fitted with a ground glass neck, a side arm with ground-glass stopcock, and a magnetic stir bar is connected through the side arm to a gas inlet tube of a Schlenk line and filled with dinitrogen. Under a gentle stream of nitrogen, tricarbonyl $\left(\left(\eta^{6}-\right.\right.$ toluene)molybdenum( $(0)(7.6 \mathrm{~g}, 27.4 \mathrm{mmol})$ is introduced, followed by tetrahydrofuran $(60 \mathrm{~mL})$. The solid dissolves to yield a pale yellow solution, which is then stirred for ea. $30 \mathrm{~min}$ at room temperature to complete the transformation to the tricarbonyl-tris(tetrahydrofuran)molybdenum( 0 ) intermediate (IR bands at $1917 \mathrm{~s}$ and $1775 \mathrm{vs} \mathrm{cm}^{-1}$ ). At this point, the solution is cooled to $0^{\circ} \mathrm{C}$ in an ice water hath and $\mathrm{I}_{2}(10.5 \mathrm{~g}, 41.5 \mathrm{mmol})$ is added, resulting in the formation of a deep red colored solution. By keeping the stopcock open to the Schlenk line ( $\mathrm{CO}$ is evolved during the process), the mixture is stirred at $0^{\circ} \mathrm{C}$ for $2 \mathrm{~h}$, and then overnight at room temperature. This treatment results in the precipitation of the product as a pale brown powder. Stirring should not be continued for a longer 
period of time, as this causes the product to redissolve in the reaction mixture with formation of unknown, presumably oxygen-containing decomposition materials, derived by oxygen abstraction from THF. A gas-chromatographic analysis of the solution indicates the presence of 1,4-diiodobutane. The product is filtered off through a glass frit, thoroughly washed with THIF, and dried under vacuum. The yield is $14.2 \mathrm{~g}(73.5 \%)$.

Anal. Calcd. for $\mathrm{C}_{12} \mathrm{H}_{24} \mathrm{I}_{3} \mathrm{MoO}_{3}$ : C, 20.8; H, 3.5. Found: C, 21.1; H, 3.8.

\section{Properties}

Triiodotris(tetrahydrofuran)molybdenum(III) is a pale brown powder. It deteriorates upon exposure to the laboratory atmosphere, but no significant change is observable upon rapid ( $<5 \mathrm{~min})$ handling in air. Its IR spectrum shows a strong vibration for coordinated THF at $835 \mathrm{~cm}^{-1}$. The IR fingerprint region overlaps almost exactly with that of the corresponding $\operatorname{MoX}_{3}(\mathrm{THF})_{3}(\mathrm{X}=\mathrm{C} 1, \mathrm{Br})$. The compound is very sparingly soluble in any common organic solvent, including chloroform, dichloromethane, and THF. Prolonged standing in a THF solution results in its decomposition as outlined above; however, by brief warming in THF followed by slow cooling, single crystals of the compound have been obtained. Its molecular stereochemistry is meridional in the solid state. ${ }^{9}$ Substitution reactions of the THF ligand by phosphine and halide ligands have been described..$^{9,15}$

\section{References}

1. M. W. Anker, J. Chatt, G. J. Leigh, and A. G. Wedd, J. Chem. Soc., Dalton Trans., 2639 (1975).

2. J. R. Dilworth and R. L. Richards, Inorg. Synth., 20, 121 (1980); J. R. Dilworth and J. Zubieta, Inorg. Synth., 24, 193 (1986); Inorg. Synth., 28, 36 (1990).

3. J. E. Armstrong, D. A. Edwards, J. J. Maguire, and R. A. Walton, Inorg. Chem., 18, 1172 (1979). 
4. D. Zeng and M. J. Hampden-Smith, Chem. Mater., 4, 968 (1992).

5. S.-Y. Roh and J. W. Bruno, Inorg. Chem., 25, 3105 (1986).

6. J. R. Dilworth and J. A. Zubieta, J. Chem. Sun, Dalton Trans., 397 (1983).

7. D. Zeng and M. J. Hampden-Smith, Polyhedron, 11, 2585 (1992).

8. E. A. Allen, K. Feenan, and G. W. A. Fowles, J. Chem. Soc., 1636 (1965).

9. F. A. Cotton and R. Poli, Inorg. Chem., 26, 1514 (1987).

10. E. E. Owens, R. Poli, and A. L. Rheingold, Inorg. Chem., 28, 1456 (1989).

11. W. Strohmeier, Chem. Ber., 94, 3337 (1961).

12. R. Poli and H. D. Mui, J. Am. Chem. Soc., 112, 2446 (1990).

13. F. Calderazzo, C. Maichle-Mössmer, G. Pampaloni, and J. Strähle, J. Chem. Soc., Dalton Trans., 655 (1993).

14. A. Barbati, F. Calderazzo, and R. Poli, Gazz. Chim. Ital, 118, 589 (1988).

15. (a) J. C. Fettinger, S. P. Mattamana, C. J. O'Connor, R. Poli, and G. Salem, J. Chem. Soc., Chem. Commun., 1265 (1995). (b) J. C. Fettinger, J. C. Gordon, S. P. Mattamana, C. J. O‘Connor, R. Poli, and G. Salem, Inorg. Chem., 35, 7404 (1996). 